\title{
A Abordagem de Resolução de Problemas por uma professora de Química: análise de um problema sobre a Combustão do Álcool envolvendo o conteúdo de Estequiometria
}

Verônica Tavares Santos Batinga

Francimar Martins Teixeira

\begin{abstract}
Resumo
Neste estudo buscou-se investigar como uma professora de Química aborda a resolução de problemas em aulas de Química do ensino médio. A pesquisa realizada se insere numa abordagem qualitativa envolvendo um estudo de caso. Nesse sentido, foram filmadas quatro aulas da professora numa turma de 3a série do ensino médio de uma escola pública de Olinda, Pernambuco, Brasil. Nestas aulas a professora propôs um problema para a turma resolver, sobre a combustão do álcool, com o objetivo de introduzir o conteúdo de estequiometria em nível qualitativo. Os resultados mostraram que a professora adotou alguns elementos da perspectiva construtivista para abordar a resolução de problemas em sala de aula. O problema elaborado e proposto pela docente foi classificado como do tipo escolar qualitativo. Durante o processo de resolução do problema os alunos puderam colocar em ação conteúdos do tipo conceitual e procedimental. A professora buscou introduzir a experimentação de forma articulada à resolução de problemas, trazendo à tona alguns aspectos: uma abordagem fenomenológica sobre a combustão do álcool; o professor como mediador das discussões em grupo, incentivando a observação, a reflexão e a formulação de hipóteses pelos alunos sobre o que acontece na combustão do álcool, tornando explícitas suas concepções prévias e a possibilidade dos alunos reformularem suas hipóteses, favorecendo a compreensão de conceitos químicos, especificamente, o de reação química.
\end{abstract}

Palavras-chave: resolução de problemas, ensino de Química, professor, estequiometria.

\begin{abstract}
The Problem Solving Approach for a Chemistry teacher: Analysis of a case on the Alcohol Combustion involving Stoichiometry

In this study we sought to investigate as a professor of Chemistry deals with the resolution of problems in classes of Chemistry of middle school. The survey is part of a qualitative approach involving a case study. In this sense, were filmed four classes of teacher in a class of 3rd series of middle school education in a public school in Olinda, Pernambuco, Brazil. In these lessons the teacher proposed a problem for the class solve, on the combustion of alcohol, with the objective of introducing the content of stoichiometry in quality. The results showed that the professor has adopted some elements of constructivist perspective to address the resolution of problems in the classroom. The problem prepared and proposed by the teacher was classified as type qualitative school. During the process of solving the problem the students could put into action type content conceptual and procedural. The teacher tried to introduce the
\end{abstract}


experimentation of articulate manner the resolution of problems, bringing to the fore some aspects: a phenomenological approach on the combustion of alcohol; the teacher as a facilitator of group discussions, encouraging observation, reflection and the formulation of hypotheses by students about what happens in the combustion of alcohol, making explicit their prior conceptions and the possibility of students rewrite their hypotheses, fostering understanding of chemical concepts, specifically, the chemical reaction.

Keywords: problem solving, chemistry teaching, teacher, stoichiometry.

\section{Introdução}

Segundo os Parâmetros Curriculares Nacionais (PCN) e as Orientações Curriculares Nacionais (OCN) um dos objetivos do ensino de Química é desenvolver estratégias didáticas centradas na resolução de problemas visando à aprendizagem de conceitos químicos articulada com a realidade natural, social e cultural, e como forma de aproximar os alunos de atividades de investigação científica desenvolvidas no contexto escolar (BRASIL, 2002; 2006). Orientar o currículo de química do ensino médio voltado para a resolução de problemas (RP) significa planejar e implementar situações abertas para instigar os alunos na busca e apropriação de estratégias adequadas não somente para darem resposta a perguntas escolares como também àquelas da realidade cotidiana.

Nessa perspectiva, é fundamental que o professor, em particular o professor de Química, por meio de sua prática em sala de aula se aproprie de referenciais teórico e metodológico que norteiam a resolução de problemas. A resolução de problemas pode ser compreendida como uma estratégia de ensino e aprendizagem em que os aspectos relativos à vivência e o contexto nos quais os alunos estejam inseridos sejam considerados durante a proposição e o processo de resolução em sala de aula. A resolução de problemas entendida nesse sentido promove uma maior aproximação dos problemas propostos, em especial nas aulas de Química, com a realidade experimentada pelos alunos em seu cotidiano e com os problemas reais que a sociedade enfrenta. Por conseguinte, precisamos ter clareza sobre como os professores estão lidando com a resolução de problemas no âmbito escolar.

Neste estudo, lidamos com a resolução de problema no contexto de aulas de Química do ensino médio. Adotamos o conceito que problema é uma situação que um sujeito ou um grupo quer ou precisa resolver e para a qual não dispõe de um caminho rápido e direto que leve à solução. Seguindo esse conceito, uma situação somente pode ser concebida como um problema na medida em que os sujeitos atribuam um reconhecimento dela como tal, e quando requer dos que a tentam resolver um processo de reflexão ou uma tomada de decisão sobre a estratégia a ser seguida no processo de resolução de problemas. Um problema é uma situação nova ou diferente do que já foi aprendido, que requer a busca de estratégias ou de conhecimentos, ou de técnicas, ou ambos, para encontrar sua solução (LOPES, 1994; POZO, 1998; GARRET, 1988). 
No contexto escolar alguns aspectos podem ser considerados pelos professores durante a elaboração e proposição de um problema, tais como: a) tipologia dos problemas (escolar, cotidiano ou científico); b) mobilizar interesse, favorecendo a motivação dos alunos, por isso a importância de seu vínculo com o dia a dia; c) ter a possibilidade de ser resolvido, utilizando uma estratégia adequada e d) possibilitar o desenvolvimento de conteúdos do tipo conceitual, procedimental (técnicas e habilidades) e atitudinal, o que implicará na construção de conhecimentos pelos alunos de forma mais articulada e integrada (Silva e Núñez, 2002). A seguir destacaremos especificamente os problemas escolares e sua classificação de acordo com Pozo (1998). E logo após algumas características dos tipos de conteúdos (CAMPOS e NIGRO, 1999).

\section{Problemas Escolares}

São aqueles que podem servir para a construção de articulações entre os problemas cotidianos e científicos. Na elaboração e proposição de problemas escolares deve-se considerar que os alunos se encontram mais próximos do conhecimento do cotidiano, que seus problemas não são os da ciência, e que partindo do seu conhecimento prévio e dos seus problemas, é preciso criar situações que os ajudem de forma progressiva a avançar no modo como resolvem problemas cotidianos para interiorizar novas formas de pensar e agir que se aproximem da resolução de problemas científicos. Ressaltamos que os problemas escolares não são concebidos como uma imitação ou aproximação forçada à pesquisa científica, e sim como uma forma de auxiliar os alunos a adquirir hábitos e estratégias de resolução de problemas mais próximos aos da ciência, assim como a distinguir as tarefas e contextos nos quais esses métodos tornam-se mais eficazes do que uma abordagem cotidiana (POZO, 1998). Essa pode ser uma forma de que os problemas escolares possam ser reconhecidos como problemas dos alunos, que eles queiram e precisam resolver e não apenas como um problema proposto pelo professor.

\section{Problema Escolar Qualitativo}

É aquele que o aluno precisa resolver através de raciocínios teóricos, baseados nos seus conhecimentos, sem necessidade de apoiar-se em cálculos numéricos, e que não requerem para a sua resolução a realização de experiências ou de manipulações experimentais (POZO, 1998). São problemas, nos quais se deve predizer ou explicar um fato, analisar situações cotidianas ou científicas e interpretá-las a partir dos conhecimentos pessoais e/ou modelo conceitual proporcionado pela ciência. O principal objetivo deste tipo de problema é fazer com que o aluno relacione os conceitos científicos com fenômenos que presenciam em seu cotidiano. A fim de buscar e estabelecer esta relação o aluno recorre ao seu conhecimento prévio procurando articular a informação que recebe e formulando hipóteses que podem contribuir com possíveis soluções para resolver o problema. Uma das vantagens deste tipo de problema é que se configuram como uma boa ferramenta para que o aluno trabalhe os conceitos científicos; seja consciente de suas ideais prévias e as discuta com os colegas em grupos. Trata-se também de um recurso útil para gerar problemas em contextos, que não sejam muito fáceis de apresentar aos 
alunos cenários nos quais possam ser manipuladas experimentalmente as variáveis existentes, por exemplo, em escolas que não dispõem de laboratório de química e/ou os professores não utilizam atividades experimentais como recurso didático para aprendizagem de conceitos químicos. Estes problemas ainda são bastante úteis para introduzir o aluno num novo assunto ou âmbito de reflexão, e que podem ser complementadas mais tarde com outro tipo de atividade didática.

\section{Problema Escolar Quantitativo}

As informações fornecidas no enunciado do problema envolvem principalmente quantidades, embora os resultados possam não ser. Nesse problema os alunos manipulam dados numéricos, trabalhando estes para se chegar a uma solução, seja ela numérica ou não. Desse modo, a estratégia de resolução do problema baseia-se no cálculo matemático, na comparação de dados e na utilização de fórmulas e equações, diferentemente do que ocorre com o problema escolar qualitativo (POZO, 1998).

De acordo com Pozo (1998) os problemas escolares quantitativos têm sido usados com frequência no contexto das aulas de Química. Esses problemas podem ser úteis quando se deseja alcançar objetivos concretos, por exemplo, ajudar o aluno a compreender os conceitos científicos por meio da aplicação de determinadas grandezas aos cálculos; permitir a aprendizagem de habilidades (conteúdos procedimentais), técnicas e algoritmos básicos para a aplicação da ciência a problemas concretos; familiarizar o aluno com a importância das medidas, da precisão, das grandezas e das unidades utilizadas para medi-las. Uma das potencialidades quanto ao uso dos problemas quantitativos é que se apresentam como um meio de familiarizar os alunos com o manejo de uma série de técnicas e algoritmos; ajuda-os e fornece-lhes os instrumentos necessários para abordar problemas mais complexos e difíceis. A quantificação, por sua vez, permite estabelecer relações simples entre as diversas grandezas científicas, o que facilita a compreensão das leis da natureza. Uma das principais limitações quanto à utilização de problemas escolares quantitativos está no fato de que estes aparecem juntos e, em muitos casos, superpostos ao problema matemático e o problema científico. É bastante comum observar que os alunos consideram ter resolvido um problema quando obtém um número, o qual se refere à solução matemática, sem parar para pensar no significado que representa este número dentro do contexto da resposta científica no qual está situado o problema. Vale ressaltar a atenção necessária para que as dificuldades matemáticas não venham a mascarar o problema de ciências, que o aluno, e às vezes o próprio professor, apenas não percebam e avaliem o problema com uma tarefa essencialmente matemática. Diante disso, é importante que os professores reflitam sobre o papel dos problemas quantitativos nas aulas de Química, em outras palavras, a quantificação deve ser entendida como um meio para aprender ciências ou um fim em si mesmo? (POZO, 1998). 


\section{Pequenas Pesquisas}

São aqueles em que se propõe para os alunos uma pergunta cuja resposta requer necessariamente um trabalho prático tanto no laboratório quanto em sala de aula (POZO, 1998). Em princípio para resolver uma pequena pesquisa os alunos teriam que identificar o objeto de estudo do problema no contexto da disciplina com base em conhecimentos anteriores. E de forma cooperativa, em grupos, possam formular hipóteses testáveis para responder o problema, como também discutir e socializar tais hipóteses, selecionar as variáveis relevantes para resolver o problema, selecionar e realizar experiências adequadas em laboratório para testar as hipóteses, conhecer técnicas experimentais para manipular corretamente e de forma segura instrumentos de medida, registrar os valores obtidos e por fim analisar os dados e sistematizar as respostas para o problema. Uma das vantagens da pequena pesquisa é porque busca relacionar os conceitos teóricos às suas aplicações práticas, ajuda na transferência de conceitos escolares para âmbitos mais cotidianos e em alguns casos, é muito motivador para os alunos. Esse último aspecto torna-o um bom instrumento no ensino através da resolução de problemas. Quanto às limitações ressaltamos que esse tipo de problema não pode ser considerado como "pesquisas" no contexto da ciência, mas representam somente uma aproximação simplificada do trabalho científico.

Quanto à tipologia dos conteúdos que podem ser abordados na resolução de problemas podemos destacar: os conceituais, procedimentais e atitudinais (CAMPOS e NIGRO, 1999).

Os conteúdos conceituais se referem ao conhecimento construído pela humanidade no decorrer da história. Assim, as explicações sobre as justificativas da ocorrência dos fatos, e conceitos são caracterizados como conteúdos conceituais. Os fatos dizem respeito aos acontecimentos históricos e naturais. Trata-se de informações pontuais e restritas, como nomes, datas e acontecimentos particulares, como por exemplo: Lavoisier foi um cientista que estudou o princípio da conservação das massas dos reagentes envolvidas numa transformação química no século XVIII. A representação dos conceitos se dá por meio de palavras que têm um significado específico e quando ouvido pelos sujeitos, produzem uma imagem mental. Por exemplo, quando um aluno ouve a palavra mistura, ele já tem uma ideia do que ela significa, atribuindo um sentido específico a essa palavra (CAMPOS e NIGRO, 1999).

Os conteúdos procedimentais se relacionam à aprendizagem de ações específicas que possibilitam a execução de determinadas tarefas quando são aprendidos. São considerados conteúdos procedimentais na área de Química aqueles relacionados a métodos investigativos, técnicas gerais, estratégias que possibilitam e facilitam a comunicação, o estabelecimento de relações entre os conceitos, habilidades manuais, etc. Autores como Pro Bueno (1995) destacam alguns conteúdos procedimentais relacionados à área de Química, dentre eles: observação de objetos e fenômenos; medição de objetos e transformações; classificação de objetos e sistemas; reconhecimento de problemas; formulação de hipóteses; identificação e controle de variáveis; 
montagem de experimentos; técnicas e investigação; análise de dados; estabelecimento de conclusões; manejo de material e realização de montagens.

Os conteúdos atitudinais dizem respeito a atitudes que os alunos assumem diante de determinados fatos, normas, regras, comportamentos e atitudes. Na área de Química tais conteúdos são classificados em dois tipos: atitudes dos alunos para com a ciência e atitudes científicas. O primeiro refere-se ao posicionamento pessoal dos alunos em relação aos fatos, conceitos e métodos com características científicas e/ou químicas. Por exemplo, o posicionamento dos alunos em relação às conquistas e inovações tecnológicas ligadas ao avanço científico, como: poluição ambiental, armas nucleares, alimentos geneticamente modificados, clonagem de células, etc. E os valores e atitudes que os alunos têm para com os cientistas, em outras palavras o que os estudantes pensam sobre os cientistas. O segundo tipo trata do estímulo dos alunos a uma conduta supostamente científica, por exemplo, ter atitudes que manifestem a curiosidade, a criatividade, o pensamento crítico e divergente, a racionalidade, e a objetividade que são características do trabalho científico, bem como a socialização, a troca de ideias, o trabalho com a autoestima dos alunos e o desenvolvimento de habilidades que lidam com a emoção.

\section{Orientações sobre o processo de Resolução de Problemas em Química}

O processo de resolução de problemas envolve analisar situações, pensar estratégias para solucioná-las, buscar informações e testar hipóteses. Desse modo, quando o aluno se envolve com a resolução de problemas ele mobiliza conceitos, raciocina, pensa e desenvolve autonomia. Os PCN preconizam que o processo de escolarização deve estar a serviço da preparação dos alunos para a vida. Assim, é esperado que os professores façam uso da resolução de problemas em suas aulas.

A seguir discutiremos alguns aspectos que caracterizam o processo de resolução de problemas em Química fundamentada na perspectiva construtivista (Gil Pérez, 1993; Grasselli e Colasurdo, 2001), em particular, a abordagem de ensino por investigação. Nessa abordagem pode-se partir da elaboração e proposição de problemas e no planejamento de distintas sequências de atividades que conduzem à resolução dos problemas propostos. O papel do professor é o de orientar a atividade, estimular a consulta entre os alunos, socializar as perguntas que surgem e sistematizar as propostas para resolver os problemas. $\mathrm{O}$ aluno quando orientado pelo professor tem a função de elaborar os fundamentos teóricos correspondentes ao problema em questão, analisando, se for o caso, as evidências experimentais com base no que foi estudado em unidades temáticas anteriores e tendo como complemento a realização de pesquisas bibliográficas e em outros momentos uma breve exposição teórica dos docentes (CACHAPUZ, JORGE e PRAIA, 2002; GRASSELLI e COLASURDO, 2001). 
A abordagem de ensino por investigação tem como objetivo que os alunos sejam capazes de construir conhecimentos sobre a ciência, cada vez mais próximos das formas de produção do conhecimento científico do que do senso comum, considerando as diferenças de contextos da ciência e da sala de aula (CAMPOS e NIGRO, 1999). Essa abordagem de ensino propicia aos alunos a vivência de habilidades características da cultura cientifica, tais como: ação e reflexão, capacidade de ouvir, trocar ideias com seus pares, ou de forma coletiva em grupos de trabalho, argumentar, desenvolver habilidades manuais e também habilidades de pensamento e emocionais. O momento de reflexão possibilita que o aluno reconstrua interiormente o que foi realizado e a partir disso vá incorporando novos conceitos a seus esquemas mentais. $\mathrm{O}$ trabalho envolvendo a resolução de problemas articulado a atividades experimentais na Química, que é desenvolvido de forma sequencial e cooperativa pode despertar o interesse e curiosidade dos alunos para a aprendizagem de Química (GRASSELLI e COLASURDO, 2001).

A seguir serão destacadas algumas características inerentes à investigação científica (Becerra Labra, Gras-Martí e Martínez-Torregrosa, 2004; 2005) que entendemos ser pertinente para caracterizar o processo de resolução de problemas buscando uma possível aproximação para o contexto da sala de aula.

1) Os problemas científicos surgem de situações problemáticas de caráter amplo e de que os sujeitos têm interesse por diversos motivos. Nesse sentido, os problemas precisam ser delimitados. Dito de outra forma, a busca de soluções para os problemas implica que realmente seja delimitado qual é o problema, o que se quer buscar, partindo inicialmente dos conhecimentos de que já se dispõe no campo específico da investigação.

2) O avanço no problema é direcionado por hipóteses, por tentativas de respostas, que devem ser colocadas à prova com o maior rigor possível. O contexto hipotético dedutivo é característico da atividade científica criativa, nesse sentido, não se pode chegar ao conhecimento científico aplicando um processo indutivo de inferência a partir de dados já conhecidos, sendo fundamental tentar construir respostas possíveis para os problemas estudados.

3) As investigações não se encontram, de um modo geral, com os dados como ponto de partida e sim com situações problemáticas confusas. As grandezas que se consideram relevantes para avançar no problema e os dados são selecionados em função da definição do problema e das hipóteses formuladas.

4) Não se raciocina em termos de certeza, nem alcança o conhecimento científico apenas observando diretamente a natureza e sim em termos de construção de hipóteses, sendo necessário duvidar sistematicamente dos resultados obtidos e de todo o processo de resolução. Isso obriga a interpretar e confrontar os resultados, mediante sua coerência com as hipóteses formuladas, a procurar diferentes caminhos para ver se se obtém o mesmo resultado, a rever a coerência global com o já conhecido nesse campo ou a ver se de fato abre e permite avançar em 
novos problemas de interesse. Isso pode conduzir a rever as hipóteses, a estratégia de resolução, ou inclusive, a reformular o problema de forma distinta.

A intenção de aproximar algumas destas características da investigação cientifica através da estratégia de resolução de problemas no espaço escolar, considerando as reais necessidades, adaptações e limitações postas por este espaço, implicarão em desenvolver formas de ensinar e aprender, em especial na disciplina de Química, que possibilitem de maneira sistematizada oportunidades de por em prática às formas de pensamento e ação da atividade científica (BECERRA LABRA, GRAS-MARTí e MARTíNEZ-TORREGROSA, 2004). Nesse sentido, apresentamos a seguir alguns indicadores de um processo de resolução de problema para a disciplina de Química, que buscam certa coerência com a metodologia de investigação científica.

1) Apresentação de enunciados não diretos (do tipo exercício): significa que o enunciado de um problema não deve conter de um modo exaustivo condições, dados, ou ferramentas que indiquem os passos a seguir antes de fazer o planejamento com o objetivo de saber o que se busca para resolver o problema. Incentivar a estruturação de enunciados dos problemas que favoreçam, em vez de bloquear, a resolução do problema no sentido de propiciar a indagação científica, como por exemplo, considerar no enunciado do problema situações que despertem o interesse do aluno, bem como as suas experiências e o contexto social e natural em que eles estão inseridos procurando buscar uma relação desses aspectos com o conhecimento químico.

2) Realização de um planejamento qualitativo da situação, imaginando a situação química, procurando levantar e delimitar de maneira precisa o problema, deixando explícito do que é que se trata de determinar e em que condição será resolvido o problema.

3) Formulação de hipóteses sobre os fatores que podem depender a grandeza buscada e sobre a forma dessa dependência, incluindo, em particular, casos limites de fácil interpretação química que necessariamente deverá contemplar o resultado do problema.

4) Elaboração com caráter tentativo de possíveis estratégias de resolução antes de proceder a essa, para possibilitar uma confrontação rigorosa das hipóteses e mostrar a coerência com o corpo de conhecimento químico de que se dispõe para resolver o problema. Não apresentar a estratégia de resolução como algo evidente e seguro.

5) Resolução de problemas como o fazer prático da estratégia planejada, verbalizando o que se faz durante o processo de resolução, procurando evitar operações mecânicas carentes de significação química.

6) Análise dos resultados obtidos a luz das hipóteses elaboradas e em particular dos casos limites considerados, sempre buscando duvidar dos resultados obtidos.

7) Consideração das possíveis perspectivas que são abertas após a resolução do problema, contemplando, por exemplo, a possibilidade de abordar o problema num nível maior 
de complexidade ou de abordar novas situações de interesse prático e teórico. Essa reflexão sobre novas perspectivas deveria incluir uma breve recapitulação sobre as dificuldades encontradas no processo de resolução do problema e a forma como foram superadas. Isso contribui para melhorar a capacidade para enfrentar os novos problemas.

Gil Pérez, Martinez Torregrosa e Sement Pérez (1988) também apontam algumas orientações que caracterizam o processo de resolução de problemas com base na metodologia de investigação científica procurando adaptá-las ao contexto escolar, nesse caso, especificamente nos remetemos à disciplina de Química. A seguir são sistematizadas estas orientações buscando caracterizar o processo de resolução de problemas em química.

1) Propor problemas oriundos de temas sociocientíficos que surgem das situações vividas pelos alunos em seu contexto social e natural através de um processo de problematização.

2) Favorecer a discussão e reflexão dos alunos sobre a relevância e o possível interesse em relação aos problemas apresentados.

3) Possibilitar análises qualitativas significativas, que ajudem a compreender o problema proposto e formular perguntas que direcionem a busca de respostas.

4) Considerar a elaboração de hipóteses como uma atividade central da resolução de problemas, sendo esse processo capaz de orientar o tratamento dos problemas e de tornar explícitas as concepções dos alunos.

5) Realizar as análises baseadas nas hipóteses elaboradas e fundamentadas teoricamente, evitando resultados carentes de significação química.

6) Conceder atenção especial à elaboração de memórias científicas que reflitam o percurso adotado na busca de respostas para o problema, ressaltando o papel da comunicação e do debate durante a resolução de problemas.

7) Enfatizar a dimensão coletiva da estratégia de resolução de problemas, por meio da socialização do conhecimento químico produzido privilegiando a interação entre o professor e alunos e alunos-alunos nos grupos de trabalho

Pozo e Postigo (1993 apud Soares et al., 2007) apresentam alguns procedimentos ou estratégias que os alunos podem mobilizar na resolução de problemas. Esses autores destacam cinco tipos de procedimentos: aquisição da informação; interpretação da nova informação; análise da informação disponível e realização de inferências sobre a mesma; compreensão e avaliação dos resultados e processo de reorganização conceitual da informação e procedimentos para comunicação e socialização dos resultados. 
De Jong (1998) sugere a incorporação da experimentação à resolução de problemas em Química. A experimentação torna-se relevante por oferecer ao aluno a oportunidade de ter experiências novas, tais como: facilitar a compreensão de conceitos científicos e ajudar a confrontar suas concepções atuais; desenvolver habilidades práticas como procedimentos de manipulação e investigação; fomentar a compreensão sobre a natureza da ciência e perceber a grande diversidade de métodos científicos; fomentar a compreensão de conceitos subjacentes a investigação científica como a definição de problemas, formulação e comprovação de hipóteses. Destacamos a seguir um exemplo de problema envolvendo o conceito de ácido que pode ser abordado nessa perspectiva em laboratórios de química.

Solicita-se aos alunos que realizem experimentos através dos quais se poderia comprovar a hipótese de que as soluções de substâncias que tenham um sabor ácido contém íons de hidrogênio. Tais experimentos implicam em reações de soluções ácidas e metais como o magnésio (DE JONG, 1998) conforme representação química da reação:

$$
\mathrm{H}^{+}(\mathrm{aq})+\mathrm{Cl}^{-}(\mathrm{aq})+\mathrm{Mg}(\mathrm{s}) \leftrightarrows \mathrm{Mg}^{2+}(\mathrm{aq})+2 \mathrm{Cl}^{-}(\mathrm{aq})+\mathrm{H}_{2}(\mathrm{~g})
$$

Se medirmos o pH (potencial de hidrogênio) deste sistema encontraremos um valor abaixo de sete indicando que o meio apresenta comportamento ácido.

Diante do exposto entendemos que a abordagem de resolução de problemas pode não ser tarefa fácil para os professores. Assim, a dificuldade em tornar um problema num objeto de reflexão científica dentro do contexto escolar é um grande desafio para o professor. Nesse sentido ficam em aberto as questões: Qual a perspectiva de ensino adotada pela professora para abordar a resolução de problemas em sala de aula? Qual a tipologia do problema abordado? $\mathrm{Na}$ abordagem de resolução de problemas busca-se introduzir conteúdos conceituais, procedimentais ou atitudinais? Quais os aspectos que caracterizam a abordagem de resolução de problemas adotada pela professora? O estudo aqui apresentado relaciona-se com essas questões e objetiva analisar como uma professora de Química aborda a resolução de problemas em aulas de Química do ensino médio.

\section{Metodologia}

Este trabalho situa-se no contexto de uma pesquisa empírica numa perspectiva de estudo de caso (YIN, 2005). O objetivo da pesquisa é analisar como uma professora de Química aborda a resolução de problemas em sala de aula de química do ensino médio. Foi proposto um problema, envolvendo o conteúdo de estequiometria, por uma docente doravante denominada de P5 a uma turma de 19 alunos da 3 a série do ensino médio de uma escola pública de Olinda, Pernambuco. 0 conteúdo de estequiometria foi selecionado pelo fato de sua abordagem em sala de aula ser caracterizada por atividades que requerem dos alunos a resolução de diversos tipos problemas. Além de ser considerado um tema central para que os alunos compreendam de uma forma ampla 
e articulada os fenômenos químicos e físicos que ocorrem ao seu redor em nível qualitativo e quantitativo (BOUJAOUDE e BARAKAT, 2003).

O perfil da professora P5 obtido a partir da entrevista apresentou a seguinte caracterização:

- Tempo de experiência profissional: leciona a disciplina de Química há 13 anos no ensino médio;

- Formação acadêmica: graduada em Licenciatura em Química e especialista em Ensino de Ciências;

- Formação em serviço: participa de um grupo formado por professores universitários, professores de Química do ensino médio e licenciandos em Química, que desenvolve trabalhos de pesquisa na área de ensino de Química e de cursos de formação permanente oferecidos pela instituição escolar que trabalha em parceria com outras instituições, como por exemplo, participou do curso intitulado "Projeto Ricardo Ferreira" promovido pela Secretaria Estadual de Educação de Pernambuco em 2005/2006.

Em seguida foram filmadas 04 aulas da docente P5 abordando os seguintes aspectos sobre o conteúdo de estequiometria: estudo qualitativo das relações estequiométricas entre reagentes e produtos numa reação química a partir do problema proposto, discussão inicial das hipóteses elaboradas pelos alunos (grupos) para responder ao problema, orientação da docente nos grupos de trabalho e sistematização com a turma.

Para categorização dos dados foram feitas análises das informações empíricas constituídas a partir da leitura recorrente de transcrições da filmagem e do problema elaborado e trabalhado por P5 com os alunos nas aulas, com o objetivo da pesquisadora se apropriar destes, permitindo a construção de unidades de significados agrupados de acordo com as suas características (BARDIN, 1979). Para analisar os dados das filmagens da sala de aula foram selecionados e transcritos episódios de falas e depoimentos simultâneos da professora P5 e dos alunos ocorridos durante as aulas, dispostos em sequências e mantendo a linguagem o mais próximo possível da forma como foi produzida.

Na figura 1 apresentamos algumas categorias construídas a partir da análise dos dados, os quais representam recortes de trechos de episódios das aulas, e do problema elaborado e trabalhado por P5 que foram videogravadas, e com base no referencial teórico de autores que fundamentaram esta pesquisa (CACHAPUZ, JORGE e PRAIA, 2002; GRASSELLI e COLASURDO, 2001; POZO, 1998, CAMPOS e NIGRO, 1999; PRO BUENO, 1995; BECERRA LABRA, GRAS-MARTÍ e MARTÍNEZ-TORREGROSA, 2004; 2005; GIL PÉREZ; MARTINEZ TORREGROSA e SEMENT PÉREZ, 1988 e SILVA e NÚÑEZ, 2002). 


\section{Características do Processo de Resolução de Problemas}

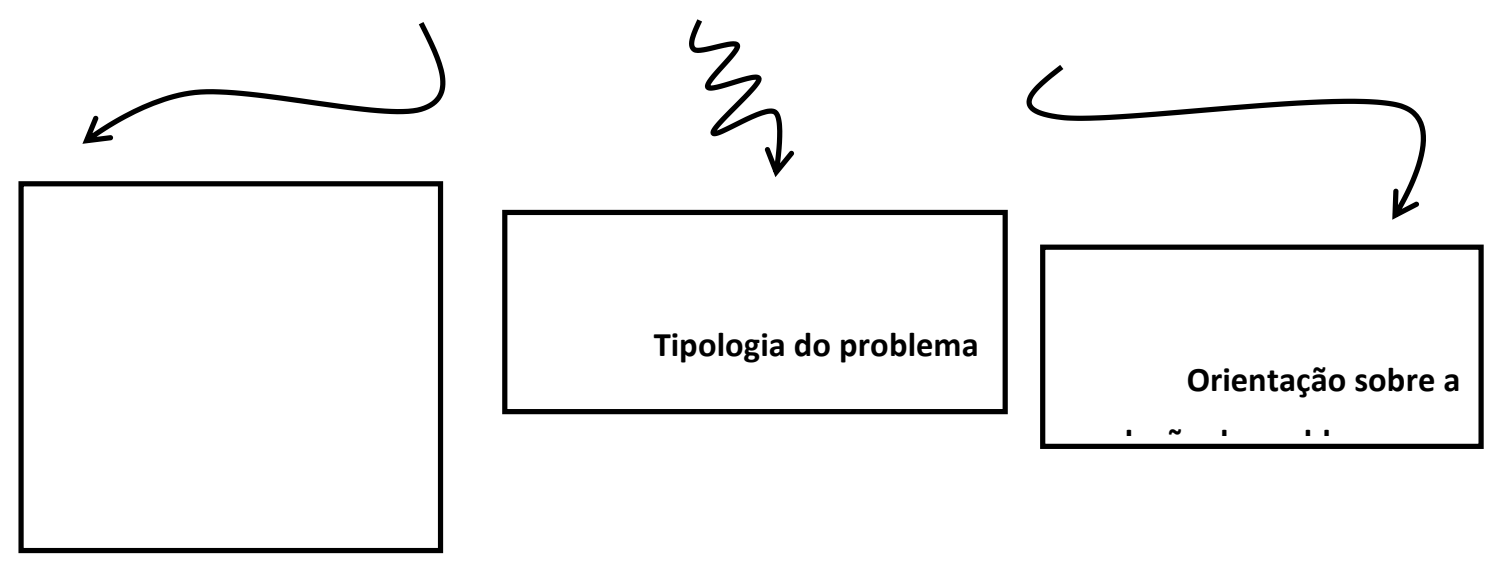

Figura 1: Características do Processo de Resolução de Problemas: categorias para análise dos dados da filmagem das aulas de Química da professora P5.

\section{Resultados e Discussão}

\section{Análise da abordagem de Resolução de um Problema proposto pela professora P5}

O problema (Cf. figura 2) proposto pela professora P5 foi analisado quanto ao aspecto de seu processo de resolução. O problema foi intitulado de "Combustão do Álcool" e trabalhado pela docente P5, em quatro aulas de Química, com 19 alunos da 3a série do ensino médio de uma escola pública na cidade de Olinda, Pernambuco. O enunciando do problema propôs uma análise da descrição esquemática de um experimento sobre a combustão do álcool que envolveu uma relação de massa entre os reagentes (álcool e oxigênio), e de que forma essa relação pode variar em função do tempo e dos volumes de recipientes que armazenaram determinada quantidade de álcool.

A observação da filmagem das aulas da professora P5 mostrou que foram formados três grupos distribuídos do seguinte modo: grupo 1 (G1): 07 alunos; grupo 2 (G2): 08 alunos e grupo 3 (G3): 04 alunos. A distribuição dos alunos nos grupos ocorreu de forma diferente da orientada pela professora conforme pode ser observado na sequência 1. A observação das aulas nos levou a entender que isso pode estar relacionado com questões de afinidade entre os alunos de cada grupo.

Nessa perspectiva, optamos inicialmente por analisar a abordagem do processo de resolução do problema proposto pela professora P5 a partir de sua interação com os alunos do grupo 3 (Cf. sequências 1 a 6) por pretendermos realizar uma análise mais aprofundada, no sentido de contribuir para atender ao objetivo da pesquisa e por termos obtido uma melhor qualidade de áudio das falas dos alunos do grupo 3 e da professora P5 no momento da transcrição, diferentemente do que ocorreu com os outros grupos. Em seguida pretendemos 
obter uma visão mais geral através da análise da interação da professora com a turma (Cf. sequência 7).

A seguir apresentamos a transcrição e a análise de recortes de episódios de falas simultâneas da professora P5 e alunos do grupo 3 e da professora P5 com a turma, ocorridos durante as duas aulas, dispostos nas sequências 1 a 7.

\section{Sequência 1}

1. P5: "Formem um círculo. Pode ser grupo de três ou quatro alunos. Qual a idéia nesse primeiro momento? Vocês vão receber um problema com três questões. Vão responder de acordo com a opinião do grupo. Não necessariamente o que está certo ou errado, mas o que agora o grupo acha certo? Qualquer coisa me chame tá certo?"

Na primeira sequência, o modo como a professora P5 iniciou a abordagem do processo de resolução do problema proposto apresenta alguns aspectos que se aproximam de uma perspectiva de ensino construtivista (Gil, 1993; Cachapuz, Praia e Jorge, 2000; 2002 e Grasselli e Colasurdo, 2001), uma vez que ela estimulou a interação entre os alunos quando propiciou o trabalho em grupo de forma cooperativa. As concepções prévias dos alunos foram valorizadas e levadas em consideração para a aprendizagem do novo conhecimento. O papel dos alunos com a mediação dessa professora foi o de elaborar hipóteses, entendidas como possíveis respostas as questões relacionadas com o problema (Cf. figura 2) e não apenas de encontrar respostas corretas.

Em seguida a professora P5 entregou a cada aluno uma ficha, na qual constou o problema (Cf. figura 2) e solicitou aos grupos que iniciassem a leitura, logo após, passou em cada grupo para reorientar as questões e esclarecer dúvidas que surgiram.

Aproximou-se um palito de fósforo acesso ao "álcool comum" contido em um recipiente, ao pegar fogo, o mesmo foi encoberto por um determinado recipiente. Em 20 segundos a chama apagou-se. $O$ mesmo procedimento foi repetido 5 vezes, porém cada vez com recipientes de tamanhos diferentes, no $2^{\circ}$ recipiente a chama apagou-se em $30 \mathrm{~s}$, no $3^{\circ}$ recipiente $40 \mathrm{~s}$, no $4^{\circ}$ recipiente 50s, no $5^{\circ}$ recipiente 50 s e no $6^{\circ}$ recipiente 50 s, conforme está ilustrado abaixo:

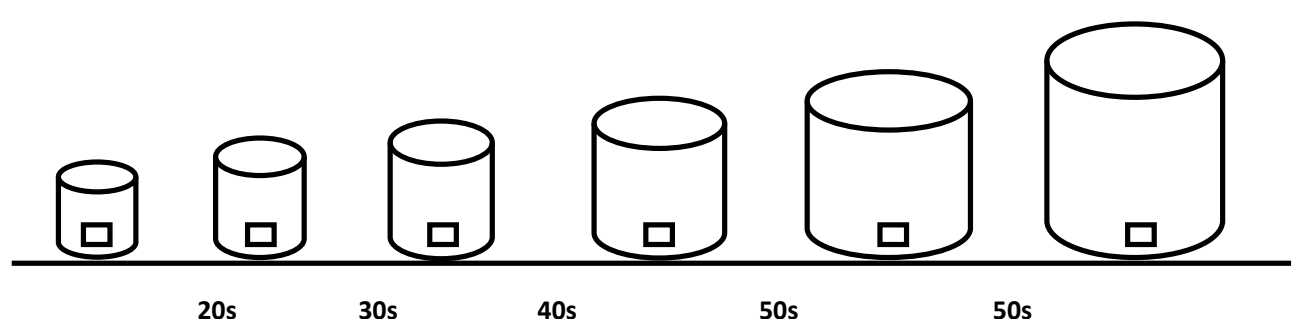

1. Proponha uma explicação para cada etapa da sequência de acontecimentos acima.

2. O que acontece com o álcool quando está queimando?

36 DOI: 10.3895/S1982-873X2014000100002

R. Bras. de Ensino de C\&T 
3. Proponha experiência(s) para comprovar as suas argumentações.

Figura 2: Problema elaborado pela professora P5

\section{Sequência 2}

1. Ax: "O que acontece com o álcool quando ele está queimando?

2. P5: E aí? A resposta é o consenso do grupo que deve ser registrado.

3. Ax: Diz aí professora.

4. P5: Você entendeu a questão?

5. Ax: Entendi professora.

6. P5: Então, explique para os seus colegas no grupo sobre o experimento para quem não leu.

7. Ay: É para explicar o que está no desenho professora?

8. Ax: Ele diz que em 20s. Tá aqui o tamanho do recipiente. Ele não fala a quantidade de álcool, mas a quantidade de oxigênio é pequena.

9. P5: Este quadradinho que está dentro do recipiente seria o álcool tá. Quando encobriu o recipiente aconteceu o que com a chama?

10. Ax: Apagou.

11. P5: Então, este desenho que está aí a chama já está apagada porque já foi encoberto e já passou o tempo. É só a sua compreensão se você está entendendo melhor o desenho.

12. Ax: O desenho eu tô entendendo legal professora.

13. Az: Eu tô. Aqui é o álcool. E já tá apagado porque foi encoberto [...]"

Na segunda sequência a professora P5 procurou instigar os alunos do grupo 3 partindo de uma pergunta relacionada com o experimento, tentando levá-los a compreensão do enunciado do problema. Para isso, forneceu alguns esclarecimentos aos alunos, incentivou a interação e discussão no grupo e buscou identificar se os alunos estavam compreendendo o esquema que representou o fenômeno da combustão do álcool no problema posto (Cf. figura 2). No entanto, P5 buscou orientar os alunos sem fornecer explicações e respostas prontas. Além de solicitar que os alunos registrassem as possíveis respostas para a primeira pergunta relativa ao problema.

Nessa perspectiva, consideramos que o modo como P5 abordou o problema proposto tornou evidente alguns elementos que caracterizam o processo de resolução de problemas de acordo com Becerra Labra, Gras-Martí e Martínez-Torregrosa (2004); Gil Peréz, Martinez Torregrosa, Senent Peréz (1988) e Gil Perez et al., (1992). Um desses elementos foi a análise qualitativa do problema tentando imaginar a situação química a fim de levantar e delimitar o 
problema, deixando explícito do que é que se tratava de resolver e em que condições. E isso muitas vezes aparece implícito nos enunciados de problemas.

Outros elementos referiram-se à proposição de problemas próximos de situações vivenciadas pelos alunos, como é o caso do fenômeno da combustão do álcool, cuja problematização pode se dá através das três questões relacionadas com o problema; o trabalho em grupo que favoreceu a discussão e reflexão pelos alunos sobre a relevância e o possível interesse em relação ao problema posto e o incentivo a elaboração de memórias escritas que retrataram o percurso adotado pelos alunos durante a busca de respostas para o problema.

\section{Sequência 3}

1. P5: "E aí? A gente vai conversar?

2. Ax: A ideia é que o recipiente varia de tamanho e por isso que com o passar do tempo a quantidade de oxigênio vai aumentando.

3. Az: Veja só professora. Escute. A quantidade de álcool é a mesma só que como o recipiente aumenta de tamanho, ai a quantidade do segundo aumenta entendeu?

4. P5: Aumenta a quantidade de que?

5. Ax e Az: a quantidade de oxigênio.

6. P5: O fato de aumentar a quantidade de oxigênio.

7. Am: Não aumenta a quantidade de oxigênio. Porque quando fecha a quantidade de oxigênio que está lá dentro não sai.

8. Az: Aumenta sim. Porque quanto maior o recipiente maior a quantidade de oxigênio.

9. Am: Só que o oxigênio que está lá dentro ele não sai. Aí com o tempo ele apaga.

10. Ax: Como o oxigênio sai se tá fechado?

11. Az: Mas você acende e fecha.

12. Am: Ei! Quando tampa-o já tá aceso.

13. Az: Mas ela quer saber o tempo em segundos que o oxigênio dura quando tampa não é?

14. P5: É.

15. P5: Acendeu. Cobriu. Quando cobriu começa a marcar o tempo. Aí o tempo que ele passou coberto e acesso foi?

16. Am: Foi de 20 segundos.

17. P5: É. A ideia é porque eu quero explicar o experimento. Ele acendeu aí cobriu nesse primeiro experimento. Quando ele cobriu aí passou 20 segundos com a chama acessa. Aí pegou 
outro recipiente queimou o álcool e cobriu. Depois de passado 30s é que a chama foi apagar. Aí pegou outro recipiente. É do mesmo tamanho?

18. Am: Não, maior.

19. Az: Não é de tamanho diferente.

20. P5: Então, foram de tamanhos diferentes?

21. Az: Então [...] (inaudível) varia de acordo com o tamanho do recipiente?

22. P5: Aí o que aconteceu com o tempo?

23. Az: Aumenta.

24. P5: Infinitamente?

25. Az: Sim.

26. Am, Ax: Não.

27. Az: Aumenta sim. Quanto maior o frasco [...]

28. P5: Qual a explicação que o grupo dá porque Az disse que iria aumentando, mas não aumentou.

29. Ax: Ficou constante.

30. P5: Por quê? Qual a idéia que vocês acham? O motivo?

31. Ax: Eu vou procurar agora.

32. P5: Pronto. Pensem nesse motivo que é o que está faltando. Vocês descreveram até aqui. Aí falta só está situação, não é? Pelo menos foi isso que eu percebi não foi Am?"

$\mathrm{Na}$ terceira sequência, consideramos que o grupo 3 avançou na compreensão do problema buscando respostas para a primeira questão. Nesse processo remetemo-nos ao que afirmam Gil Peréz, Martinez Torregrosa e Senent Peréz (1988) sobre a dimensão coletiva da estratégia de resolução de problemas, que se dá por meio da socialização do conhecimento que vai sendo construído através da interação entre o professor e alunos e alunos-alunos no trabalho em grupo. Isto vem a ressaltar o papel da comunicação e do debate durante a resolução de problemas.

Considerando os estudos de Becerra Labra, Gras-Martí e Martínez-Torregrosa (2004) a sequência 3 nos sugere que o avanço no entendimento do problema foi direcionado pela tentativa dos alunos de construírem possíveis respostas ao problema estudado, as quais podem ser posteriormente confrontadas com base no pensamento químico e na experimentação. Assim, para esses autores quando isso é oportunizado durante o processo de resolução de problemas, em sala de aula, privilegia-se o desenvolvimento do pensamento hipotético dedutivo pelos 
alunos, que é característico da atividade científica, em detrimento do predomínio de um processo indutivo de inferência a partir de dados já conhecidos, bastante característico da resolução de exercícios em química.

Destacamos ainda que a interação entre alunos-alunos e os alunos e a professora P5 na sequência 3 pareceu-nos indicar que o conhecimento químico não é alcançado apenas por observação direta da natureza e sim em termos de construção de hipóteses. Nesse sentido, segundo afirmam Becerra Labra, Gras-Martí e Martínez-Torregrosa (2004) não se raciocina em termos de certeza, portanto, é necessário duvidar das possíveis respostas que surgem durante o processo de resolução de problemas, em particular, de química.

\section{Sequência 4}

1. Az: "Professora veja só. Aqui eu pensei uma lógica assim:

2. P5: Diga.

3. Az: O tempo máximo que ele agüenta com essa quantidade de álcool é cinqüenta segundos não importa o tamanho do recipiente.

Am: Importa sim!

4. P5: O que tá determinando?

5. Az: Mas eu tô falando daqui para cá (refere-se aos recipientes 4 a 6). Não tô falando daqui para cá porque daqui para cá a gente já fez.

6. P5: Aí o que tem daqui para cá?

7. Az: Aí do quarto para cá não importa o tamanho do recipiente, mas sim a quantidade de álcool, que se tivesse maior poderia ser que agüentasse mais tempo no caso.

8. P5: Então, a diferença está na quantidade de álcool? O álcool está diminuindo? O que está acontecendo aí?

9. Az: De álcool porque aqui tá constante.

10. Ax: Então a quantidade de álcool é a mesma. Muda o tamanho do recipiente aí.

11. Az: Pelo que eu entendi o negócio do álcool se fosse maior (a quantidade de álcool) podia ser que agüentasse mais tempo porque o pote é maiorzinho no caso.

12. P5: É o pensamento do grupo? Todo mundo entrou num consenso? A idéia é entrar num consenso.

13. Az: Sim professora. Mas tem que entrar num consenso que esteja certo. 
14. P5: A gente vai discutir. Cada um vai colocar a sua contribuição e a gente vai chegar num raciocínio junto. Não se preocupem. $O$ importante é o grupo chegar num consenso e ter um pensamento.

15. P5: Am entendeu o que tá acontecendo e Cm?

16. Am, Cm: Calaram.

17. P5: [...] uma vez registrado o que pensam da primeira pergunta passem para a segunda pergunta".

A sequência 4 (Cf. turnos 3 a 11) apontou que os alunos $A x$ e Az começaram a perceber que há certa relação entre a quantidade de oxigênio e álcool no fenômeno da combustão. E que estas quantidades influenciam o tempo de duração da combustão. Eles também perceberam que a quantidade de álcool permaneceu constante nos seis recipientes e que houve um aumento na quantidade de oxigênio, pelo fato dos recipientes aumentarem sua capacidade de volume na sequência esquemática apresentada no problema. Isso vem a concordar com Becerra Labra, GrasMartí e Martínez-Torregrosa (2004) quando afirmam que o processo de resolução de problema possibilita aos alunos a formular hipóteses sobre os fatores que podem depender da grandeza buscada e a forma desta dependência. Nesse caso, se faz necessário uma interpretação química que deverá contemplar o resultado do problema.

Em particular, consideramos que o reconhecimento e delimitação do problema, com a mediação da docente P5 pode ter auxiliado os alunos Ax e Az a proporem uma explicação em nível macroscópico para o esquema que representou um experimento sobre a combustão do álcool, em que variáveis como volume do recipiente, tempo de combustão e quantidade de reagentes sofreram modificações nas seis etapas apresentadas. E também a fazerem previsão sobre o experimento o que se tornou evidente no turno 11 da sequência 4.

\section{Sequência 5}

1. Az: "A segunda é porque ele passa do estado líquido para o gasoso quando está pegando fogo. Mas esse aqui (terceira questão) eu não sei fazer.

2. Ax: É montar uma experiência para a gente verificar não é?

3. P5: Esse terceiro você vai construir um experimento para comprovar. O que você disse na questão um?

4. Ax: Devido o tamanho do recipiente o oxigênio aumenta.

5. Az: A quantidade álcool é a mesma, mas o oxigênio varia de acordo com o tamanho de cada recipiente.

6. P5: Você pode imaginar. O que você poderia pensar para provar isso que está dizendo? Como você pode provar isso aí? Qual seria um experimento para você provar o que tá dizendo?

R. B. E. C. T., vol 7, núm. 1, jan-abr.2014 ISSN - 1982-873X 
7. Az: Aí no caso eu pensei assim: a quantidade de álcool é a mesma, então o álcool fica constante, mas nos frascos 4, 5 e 6 a quantidade de oxigênio é maior.

8. P5: E aí?

9. Am: Eu discordo.

10. P5: Az tem um posicionamento. Vocês concordam, discordam por quê?

11. Az: Mais quanto maior o recipiente maior a quantidade de oxigênio?

12. P5: Vocês acham?

13. Az: O tempo tá constante por causa da quantidade de álcool. Se aumentar a quantidade de álcool aumentava os segundos.

14. P5: E aí concordam? Se sim registrem.

15. Az: Registra".

Na sequência 5 (Cf. turno 1) destacamos a resposta do aluno $\mathrm{Az}$ a segunda pergunta do problema (Cf. figura 2): O que acontece com o álcool quando está queimando? Observa-se que $\mathrm{Az}$ concebe a combustão do álcool, que é uma reação química, como uma transformação física. Isto corrobora com resultados de pesquisas desenvolvidas por Mortimer e Miranda (1995) que mostraram que os alunos centram suas explicações sobre fenômenos classificados como reações químicas nas mudanças perceptíveis, como por exemplo, nas mudanças de estado físico, que ocorrem com as substâncias reagentes e produtos, neste caso, com o álcool quando entra em combustão. Este resultado também nos informa que os alunos nem sempre reconhecem as entidades químicas que se transformam e as que permanecem constantes.

A compreensão dos alunos sobre o que é uma reação química é primordial para introdução do estudo da estequiometria. Entretanto, muitos alunos possuem concepções sobre reação química diferentes da aceita pela cultura científica (Mortimer e Miranda, 1995) o que se constitui como uma dificuldade para a aprendizagem de estequiometria.

Na sequência cinco também foram constatados alguns elementos que caracterizam o processo de resolução de problemas conforme Becerra Labra, Gras-Martí e Martínez-Torregrosa (2004) e Gil Peréz, Martinez Torregrosa e Senent Peréz (1988), por exemplo: a importância da comunicação e do debate na resolução do problema que envolveu a combustão do álcool, uma vez que o aluno $A z$ buscou entender o que foi solicitado no enunciado da terceira questão relativa ao problema posto (Cf. figura 2) através da interação com a professora P5 e com o aluno Ax (Cf. turnos 2, 3 e 6); a elaboração e confronto de hipóteses quando o aluno Az reafirmou sua hipótese sobre a primeira questão, o que pareceu gerar diferentes opiniões no grupo 3 pelo fato da aluna Am discordar de Az. Além disso, P5 propôs que as hipóteses elaboradoras pelo grupo 3 para 
responder a $1^{\text {a }}$ e $2^{\underline{a}}$ questões relacionadas com o problema (Cf. figura 2 ) fossem colocadas a prova através da experimentação, e continuou enfatizando a necessidade de elaboração de memórias por meio de registro escrito das possíveis respostas formuladas pelo grupo 3.

\section{Sequência 6}

1. Az: "No terceiro tá pedindo uma experiência que comprove essa ou pode ser outra experiência?

2. P5: Que comprove a sua justificativa.

3. Ax: No fogo também é? A terceira, professora?

4. Az: Professora a gente colocou assim: Se aumentar a quantidade de álcool aumentava a quantidade de segundos. Resumindo, aqui a gente vai fazer uma experiência de acordo com a nossa explicação.

5. Am: É só desenhar gente.

6. Az: E esse segundo ele passa de líquido para gasoso.

7. P5: Aí tem como explicar isso?

8. Az: Tem

9. P5: Como é que você provaria isso aí usando experimento?

10. Az: Quando a água ferve. A mesma coisa acontece com o álcool.

11. P5: É uma justificativa. Agora o grupo tem que entrar num consenso".

Analisando a sequência 6 percebemos que Az passou a compreender o que é para fazer na terceira questão, o que não aconteceu na sequência 5 . Pareceu-nos ser um consenso do grupo 3 propor um experimento, representado por um desenho, para justificar as respostas a 1 a e $2^{\underline{a}}$ questões relativas ao problema proposto (Cf. figura 2). A seguir podemos observar na figura 3 as respostas do grupo 3 (G3) ao problema.

Aproximou-se um palito de fósforo acesso ao "álcool comum" contido em um recipiente, ao pegar fogo, o mesmo foi encoberto por um determinado recipiente. Em 20 segundos a chama apagou-se. O mesmo procedimento foi repetido 5 vezes, porém cada vez com recipientes de tamanhos diferentes, no $2^{\circ}$ recipiente a chama apagouse em $30 \mathrm{~s}$, no $3^{\circ}$ recipiente $40 \mathrm{~s}$, no $4^{\circ}$ recipiente $50 \mathrm{~s}$, no $5^{\circ}$ recipiente 50 s e no $6^{\circ}$ recipiente 50s. Conforme está ilustrado abaixo: 


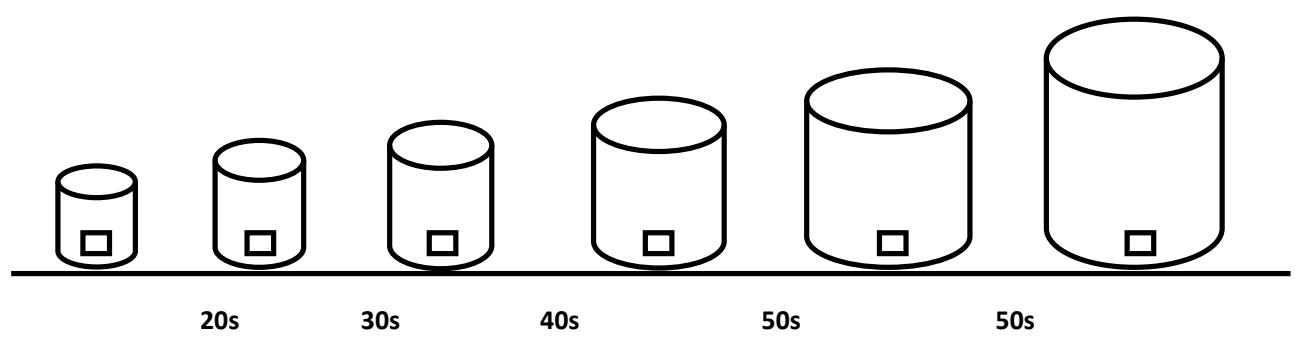

1. Proponha uma explicação para cada etapa da sequência de acontecimentos acima.

G3: "Em cada recipiente a quantidade de álcool é a mesma, mas o oxigênio varia de recipiente. A partir do quarto recipiente a quantidade de álcool é a mesma, por isso permanece constante. Se aumentar a quantidade de álcool aumentaria os segundos porque o recipiente varia de tamanho. $O$ álcool que determina o tempo".

2. O que acontece com o álcool quando está queimando?

G3: "Ele passa do líquido para o gasoso"

3. Proponha experiência(s) para comprovar as suas argumentações.

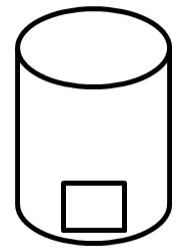

$50 \mathrm{~s}$

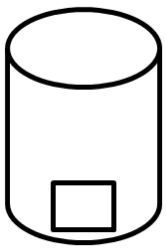

$70 \mathrm{~s}$

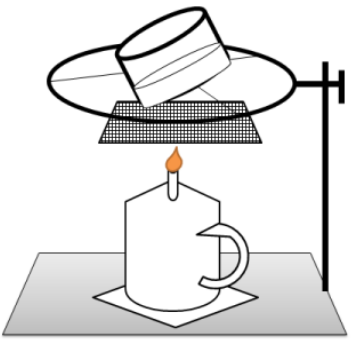

Figura 3: Respostas do grupo três ao problema proposto pela professora P5

Outro aspecto a destacar é que a articulação entre a resolução de problemas e a experimentação pareceu ser uma estratégia sugerida por P5 (Cf. figura 2 - questão 3) como uma forma dos alunos confrontarem as hipóteses formuladas para resolver o problema, o que concorda com proposta de De Jong (1998) quando afirma que a experimentação torna-se relevante por oferecer ao aluno a oportunidade de ter novas experiências, dentre elas: facilitar a compreensão de conceitos científicos e ajudar a confrontar suas concepções atuais; fomentar a compreensão de conceitos subjacentes à investigação científica como a definição de problemas, formulação e comprovação de hipóteses.

Em linhas gerais, a análise das interações entre os sujeitos apresentadas nas sequências de 1 a 6, especificamente, quanto à discussão do grupo 3 sobre as três questões relacionadas com o problema proposto (Cf. figura 2) nos levou a classificar tal problema como do tipo escolar 
qualitativo (POZO, 1998). Além disso, nos permitiu apontar que os alunos colocaram em ação alguns conteúdos procedimentais destacados por Pro Bueno (1995), tais como:

- na primeira questão, a observação de uma sequência esquemática que representou o fenômeno da combustão do álcool e teve a finalidade de descrever qualitativamente os dados e registrar o que foi observado. Também nessa questão, a identificação de variáveis procurando delimitar as que foram relevantes para resolver o problema e o estabelecimento de relações de dependência entre estas, em particular perceberam a dependência entre certa quantidade de álcool e de gás oxigênio que reagem na combustão do álcool;

- interpretação do enunciado do problema proposto com o objetivo de reconhecê-lo, buscando identificar o motivo pelo qual se estudou tal problema e a apropriação do contexto do problema, nesse caso, a combustão do álcool comum;

- na segunda questão, a formulação de hipóteses no sentido de estabelecer ideias testáveis para resolver o problema posto e deduzir previsões a partir de um conhecimento teórico prévio;

- na terceira questão sugeriram montagens experimentais visando selecionar experiências adequadas para testar as hipóteses formuladas na segunda questão.

\section{Sequência 7}

1. P5: "O que a gente discutiu na sala na aula anterior? (se refere a 1 e 2 aula).

2. P5: Foram quantos recipientes?

3. Ak: Foram seis.

4. P5: Deixa-me recapitular aqui (no quadro). 1, 2, 3 (se refere à sequência de recipiente e coloca o esquema do experimento do enunciado do problema no quadro).

5. P5: Tempo zero não foi?

6. Ar: Não. 20, 30, 40, 50, 50 e 50 .

7. P5: Aqui porque a chama apagou? A gente chegou a uma conclusão. Qual foi?

8. P5: Nos três primeiros recipientes por que a chama apagou?

9. Ak: Foi pouco álcool

10. Az: Foi pouco oxigênio gente.

11. P5: E nas três seguintes por que apagou?

12. Turma; Az: Foi porque tinha pouco álcool.

13. Ak: Para muito oxigênio.

14. Az: Por isso que o tempo foram os mesmos independentes do tamanho do recipiente.

R. B. E. C. T., vol 7, núm. 1, jan-abr.2014 ISSN - 1982-873X 
15. Ak: Tinha a mesma quantidade de álcool.

16. P5: Vocês já ouviram falar do triangulo do fogo? Precisa de uma faísca. Se eu colocar uma faísca em contato com o ar? $O$ ar é oxigênio? $O$ ar é uma substância ou uma mistura de substâncias?

Turma: uma mistura.

17. P5: $O$ ar é formado por um componente ou mistura de componentes?

18. Turma: Vários componentes.

19. P5: E o oxigênio seria um destes?

20. Az: O mais abundante né.

21. P5: Então, para queimar o triângulo do fogo precisa da chama ou da faísca, do combustível no caso o álcool ou parafina e do oxigênio que a gente chama de comburente. Então aqui (nos três primeiros recipientes) faltou oxigênio que é o comburente. E nos outros três seguintes faltaram o combustível. Então, se eliminar um desses três aqui (refere-se à faísca, combustível, comburente) apaga a chama ok? Ficou claro que para queimar precisa da faísca, do gás oxigênio e do álcool.

22. P5: E cadê o álcool que acabou? O que aconteceu com ele? Nos três primeiros frascos apagou a chama porque acabou o oxigênio. Para onde foi o oxigênio? Em Amr? O que aconteceu com ele? Acabou?

23. Amr: Transformou em gás carbônico.

24. P5: Será?

25. Amr: Tô chutando

26. P5: Nos três primeiros frascos o que aconteceu com o álcool? Acabou. O que é acabar? E deixar de existir?

27. Amr: Não.

28. P5: Então Amr o que seria se transformar?

29. Amr: Passar a ser outra substância.

30. P5: A ser outra substância. E o restante acha o que?

31. Turma: É isso ai"'.

A docente P5 na sequência 7 procurou sistematizar as respostas da turma ao problema proposto, fazendo um resgate da 1a questão e buscando iniciar um aprofundamento da 2a Contudo, ainda não foi percebida uma discussão sobre a 3a questão do problema (Cf. figura 2). Esse modo de abordar a resolução do proposto pela professora P5 guarda aproximação com o 
que afirmam Gil Peréz, Martinez Torregrosa e Senent Peréz (1988) e Gil Peréz (1993) sobre a necessidade de considerar a dimensão coletiva da estratégia de resolução de problemas por meio da socialização do conhecimento produzido, privilegiando a interação entre o professor e alunos e alunos-alunos nos grupos de trabalho.

Consideramos que a forma de mediação da docente P5 durante a resolução do problema (Cf. sequência 7) oportunizou os alunos a mobilizarem procedimentos citados por Pozo e Postigo (1993 apud Soares et al., 2007) relacionados com: a aquisição e interpretação da informação do enunciado do problema; análise da informação disponível e formulação de hipóteses sobre a mesmo; processo de reorganização conceitual da informação e procedimentos para comunicação e socialização dos resultados.

\section{Considerações Finais}

No que se refere à abordagem de resolução do problema (Cf. figura 2) adotada pela professora P5, concluímos que a sua forma de abordar um problema qualitativo sobre estequiometria, no contexto da combustão do álcool, se aproximou de alguns aspectos da perspectiva de ensino por investigação, uma vez que durante o processo de resolução do referido problema (Cf. sequências 1 a 6), os alunos do grupo 3 vivenciaram um contexto de aprendizagem que interagiram de maneira dialógica com o problema a ser resolvido, por meio da reflexão, da capacidade de ouvir e argumentar, de trocar ideias com seus pares; desenvolveram habilidades de pensamento e emocionais; e buscaram resolver um problema cujo contexto se aproxima de sua realidade cotidiana. É relevante destacar que segundo Grasselli e Colasurdo (2001) estas habilidades se aproximam das características da cultura científica.

Outro ponto que podemos concluir a partir da análise das aulas da professora P5 foi que sua forma de conduzir o processo de resolução do problema (Cf. figura 2) traz subjacente alguns aspectos característicos de posicionamentos construtivistas. Por exemplo, foi observada a busca de uma dependência entre o processo de resolução do problema e o conteúdo de estequiometria e reação química inseridos no problema. Outro exemplo evidenciado nas sequências 1 a 6 , foi que a representação mental, a compreensão e as ideias prévias do grupo 3 acerca do que é uma reação química foram aspectos que influenciaram no processo de resolução do problema (Cf figura 2), conforme preconiza Pozo (1998) quando discorre acerca dos aspectos que influenciam no processo de resolver problemas.

A análise das sequências 6 e 7 possibilitou concluir, de um modo geral, que a experimentação foi introduzida pela docente P5, nas aulas sobre estequiometria, numa perspectiva construtivista segundo Grasselli e Colasurso (2001) e Guimarães (2009) por trazer a tona alguns elementos: permitir uma abordagem fenomenológica da combustão do álcool; apontar o papel do professor como mediador da discussão; incentivar o pensamento reflexivo 
sobre o fenômeno observado e a elaboração de hipóteses; possibilitar o confronto das hipóteses iniciais dos alunos sobre o que acontece na combustão do álcool; tornar explícita as concepções prévias dos alunos sobre a combustão do álcool; conduzir os alunos formulação de novas hipóteses e facilitar a compreensão de conceitos químicos, especificamente, o de reação química.

A partir da análise dos resultados da filmagem da aula da professora P5 colocamos algumas reflexões acerca da abordagem de resolução de problemas na sala de aula de química. Em linhas gerais, inferimos que o modo como os professores abordam a resolução de problemas em sala de aula pode estar refletindo uma reprodução do que eles aprenderam e vivenciaram enquanto alunos na disciplina de química, e em sua formação inicial enquanto futuros professores. Nesse contexto, entendemos que alguns limites podem se apresentar à prática do professor, principalmente, se ele não conhece, não aprendeu e nem vivenciou a estratégia de resolução de problemas quer seja como estudante de química, em sua formação inicial ou em serviço.

Dentre os limites, destacamos o fato do professor possuir dificuldade em formular problemas no contexto escolar. Diante disso, autores como Soares, Cavalieri, Teixeira et al., (2007) afirmam ser fundamental que o professor considere alguns aspectos essenciais na formulação de um problema, tais como: saber escolhê-lo, pois ele deve ser interessante e compatível com o grau de conhecimento dos indivíduos; de interpretação fácil; que seja instigador; que motive os alunos; de linguagem simples e familiar; de acordo com o percurso escolar tanto individual quanto coletivo e que permitam aos alunos experimentar, resolver, desenvolver e encontrar sua solução.

É também necessário que o professor ao elaborar problemas em sala de aula possa considerar algumas dificuldades apresentadas pelos alunos quando resolvem problemas, dentre elas: dificuldade de utilizar o raciocínio lógico, em compreender o enunciado, em representar mentalmente o problema e em mobilizar os conhecimentos teóricos que geralmente são insuficientes para resolver o problema (MARTíNEZ-LOSADA, GARCÍA-BARROS, MONDELO-ALONSO et al., 1999).

Outro aspecto a considerar, é que se os professores têm procurado introduzir problemas em sala de aula, pode ser que os alunos não o tenham reconhecido como tal. Essa falta de reconhecimento do problema pode não mobilizar os alunos e desafiar sua curiosidade para a busca de solução. Então, não é apenas suficiente que o professor proponha o problema, mais que procure despertar o interesse e curiosidade dos alunos em enfrentar o problema como seu, a fim de que eles possam resolvê-lo (GIL, MARTINEZ-TORREGROSA, RAMIREZ, et al., 1992).

Nessa perspectiva, os professores podem apresentar dificuldades em conduzir a resolução de problemas em sala de aula, uma vez que essa estratégia requer do professor conhecimentos, habilidades e atitudes que oriente os alunos a: identificar o problema proposto e reconhecê-lo 
como seu; instigue-os a formular hipóteses, como tentativas de possíveis respostas para resolver o problema; propor uma sequência de atividades a serem desenvolvidas pelos alunos e articuladas ao problema; solicitar que eles planejem estratégias teóricas e/ou práticas para realizar as atividades e resolver o problema; orientar na busca de fontes de informação, materiais e recursos que fundamente e permita executar as estratégias planejadas, orientar os alunos na seleção de informações relevantes para resolver o problema através do registro de dados, observações e interpretação dos dados; solicitar que eles elaborem respostas mais fundamentadas com base nas estratégias utilizadas para realizar as atividades; gerenciar os trabalhos em grupos; orientar os alunos quanto à forma de socializar as respostas para o problema, confrontando-as com a de outros grupos e solicitar que eles avaliem as respostas obtidas de forma articulada aos procedimentos utilizados para resolver o problema (BECERRA LABRA, GRAS-MARTí e MARTíNEZ-TORREGROSA, 2004; 2005; GIL PÉREZ, 1993; SOARES, CAVALIERI, TEIXEIRA et al., 2007; PERALES PALACIOS, 1993).

Diante do exposto, propomos como uma possibilidade que busca minimizar, e na medida do possível romper com essas limitações, as quais podem ser impostas ao professor para abordar a estratégia de resolução de problemas no contexto escolar, modalidades de formação continuada organizadas através de parcerias entre escolas e instituições formadoras, que privilegiem a adoção de modelos didáticos e pedagógicos que correspondam às reais prioridades e necessidades dos professores. Também, que possam subsidiar as novas exigências requeridas no ofício do professor no que diz respeito à abordagem de resolução de problemas com base em resultados de pesquisa nesta área (SCHNETZLER e ARAGÃO, 1995; SCHNETZLER, 2002). Além disso, que proponham alternativas para acompanhar e auxiliar no desenvolvimento teórico e prático e propiciar a troca de experiências vivenciadas com a estratégia de resolução de problema, no lócus de atuação do professor, que é a sala de aula. Ressaltamos que esta modalidade de formação também pode ser transposta para formação inicial adequando ao contexto de cada instituição de ensino superior.

Entretanto, consideramos que a implementação de tal proposta não é algo tão simples e fácil, pois se exige investimento das instituições formadoras, no sentido de incentivar e preparar, e que haja interesse e disponibilidade dos professores formadores na área de Educação em Ciências/Química para trabalhar com estratégias de ensino que abordem a resolução de problemas tanto no âmbito acadêmico, quanto no espaço escolar. Para isso, acreditamos ser fundamental que os professores formadores se disponibilizem e compartilhem dessa concepção de modalidade de formação inicial e continuada.

Do outro lado é preciso que a escola possa estar aberta para participar desta modalidade de formação contínua em parceria com instituições formadoras dando o apoio necessário e, principalmente, que os professores de química desejem participar e disponibilizem suas salas de 
aulas para trabalhar em conjunto com os professores formadores possibilitando compartilhar experiências e uma articulação entre teoria e prática no âmbito escolar e acadêmico.

Nessa perspectiva, essa proposta vem corroborar com que afirma Gil, MartinezTorregrosa, Ramirez et al. (1992) acerca da necessidade dos professores vivenciarem estratégias de resolução de problemas quer seja na sua formação inicial ou continuada entendida como um suporte teórico-metodológico que possibilite a concretização desta estratégia nas aulas de ciências/química.

\section{Referências}

BARDIN, L. Análise de Conteúdo. Tradução Luís Antero Neto. Lisboa: Edições 70, 1979.

BECERRA LABRA, C.; GRAS-MARTÍ, A.; MARTínEZ-TORREGROSA, J. Análisis de la resolución de problemas de física em secundaria y primer curso universitário em clile. Enseñanza de las ciencias, v.22, n. 2, p. 275-286, 2004.

BECERRA-LABRA, C.; GRAS-MARTÍ, A.; MARTínEZ-TORREGROSA, J. ¿De verdad se enseña a resolver problemas en el primer curso de física universitaria? La resolución de problemas de "lápiz y papel” en cuestión. Revista Brasileira de Ensino de Física, v. 27, n. 2, p. 299-308, 2005.

BOUJAOUDE, S.; BARAKAT, H. Students' problem solving strategies in stoichiometry and their relationships to conceptual understanding and learning approaches. Electronic Journal of Science Education, v.7, n. 3, mar. 2003.

BRASIL. Parâmetros curriculares nacionais: ensino médio. Brasília (DF), Secretaria de Educação Média e Tecnológica: MEC, 2002.

BRASIL. Orientações curriculares para o ensino médio: ciências da natureza, matemática e suas tecnologias. Brasília (DF), Secretaria de Educação Básica: MEC, 2006.

CACHAPUZ, A.; PRAIA, J.; JORGE, M. Ciência, educação em ciência e ensino das ciências. Lisboa: Ministério da Educação, 2002.

CACHAPUZ, A.; PRAIA, J.; JORGE, M. Reflexão em torno de perspectivas do ensino das ciências: contributos para uma nova orientação curricular: ensino por pesquisa. Revista de Educação, v, IX, n. 1, p.69-79, 2000.

CAMPOS, M. C. C.; NIGRO, R. G. Didática de ciências: o ensino-aprendizagem como investigação. São Paulo: FTD, 1999.

DE JONG, O. Los experimentos que plantean problemas em las aulas de química: dilemas y soluciones. Enseñanza de las Ciências, v. 16, n. 2, p. 305-314, 1998. 
GARRET, R. M. Resolución de problemas y creatividad: implicaciones para el currículo de ciencias. Enseñanza de las Ciencias, v. 6, n. 3, p. 224-230, 1988.

GIL, D.; MARTINEZ-TORREGROSA, J.; RAMIREZ, L.; DUMAS-CARRÉ, A.; GOFFARD, M.; CARVALHO, A. M. P. Questionando a didática de resolução de problemas: elaboração de um modelo alternativo. Caderno Catarinense de Ensino Física, Florianópolis, v. 9, n. 1, p. 7-19, 1992.

GIL PERÉZ, D. Contribución de la historia y de la filosofía de las ciencias al desarrolo de um modelo de enseñanza/aprendizaje como investigación. Enseñanza de las Ciencias, v. 11, n.2, p. 197-212, 1993.

GIL PERÉZ, D.; MARTINEZ tORREgROSA, J.; SENENT PEREZ, F. El fracasso en la resolución de problemas de física: una investigación orientada por nuevos supuestos. Enseñanza de las Ciencias, v. 6, n.2, p. 131-146, 1988.

GRASSELLI, M. C.; COLASURDO, V. Reacciones químicas: un enfoque integrado. Como se experimenta, out., 2001.

GUIMARAES, C. C. Experimentação no ensino de química: caminhos e descaminhos rumos à aprendizagem significativa. Química Nova na Escola, v. 31, n. 1, ago. p. 198-202, 2009.

LOPES, J. B. Resolução de problemas em física e química: modelo para estratégias de ensinoaprendizagem. Lisboa: Texto Editora, 1994.

MARTíNEZ-LOSADA, C.; GARCÍA-BARROS, S.; MONDELO-ALONSO, M.; VEGA-MARCOTE, P. LoS problemas de lápiz y papel en la formación de professores. Ensenãnza de las ciencias, v. 17, n. 2, p. 211-225, 1999.

MORTIMER, E. F; MIRANDA, L. C. Concepções de estudantes sobre reações químicas. Química Nova na Escola, n. 2, nov. p. 23-26, 1995.

PERALES PALACIOS, F.J. La resolución de problemas: uma revisión estructurada. Enseñanza de las ciências, v. 11, n. 2, p. 170-178, 1993.

POZO, J. I. (Org.). A solução de problemas: aprender a resolver, resolver para aprender. Porto Alegre: Artmed, 1998.

PRO BUENO, A. Reflexiones para la selección de contenidos procedimentales en ciencias. Alambique - Didáctica de las Ciencias Experimentais, v. 6, p. 77-87, 1995.

SCHNETZLER, P. R.; ARAGÃO, R. M. R. Importância, sentido e contribuições de pesquisas para o ensino de química. Revista Química Nova na Escola, n.1, maio, p. 27-31, 1995.

SCHNETZLER, R. P. Concepções e alertas: sobre formação continuada de professores de Química. Revista Química Nova na Escola. São Paulo, n.16, p.15-20, 2002. 
SILVA, S. F.; NÚÑEZ, I. B. O ensino por problemas e trabalho experimental dos estudantes: reflexões teórico-metodológicas. Química Nova, v. 25, n. 6b, p. 1197-1203, 2002.

SOARES, B. A.; CAVALIERI, A. M. A. P.; TEIXEIRA, T. C. C. C.; GARCIA, T. C. As concepções implícitas de professores acerca de resolução de problemas. Psicologia para América Latina, n. 9, p. 1-16, abr. 2007.

YIN, R.K. Estudo de Caso: planejamento e métodos. 3. ed. Porto Alegre: Bookman, 2005.

Verônica Tavares Santos Batinga: Professora do Departamento de Química da Universidade Federal Rural de Pernambuco. veratsb@gmail.com

Francimar Martins Teixeira: Professora do Departamento de Educação da Universidade Federal de Pernambuco. francimarteixeira@gmail.com 